\title{
Linking a Storm Water Management Model to a Novel Two- Dimensional Model for Urban Pluvial Flood Modeling
}

\author{
Yuhan Yang ${ }^{1,2} \cdot$ Leifeng Sun ${ }^{1,2} \cdot$ Ruonan $\mathrm{Li}^{1,2} \cdot$ Jie Yin $^{1,2,3} \cdot$ Dapeng Yu
}

Published online: 25 May 2020

(C) The Author(s) 2020

\begin{abstract}
This article describes a new method of urban pluvial flood modeling by coupling the 1D storm water management model (SWMM) and the 2D flood inundation model (ECNU Flood-Urban). The SWMM modeling results (the overflow of the manholes) are used as the input boundary condition of the ECNU Flood-Urban model to simulate the rainfall-runoff processes in an urban environment. The analysis is applied to the central business district of East Nanjing Road in downtown Shanghai, considering 5-, 10-, 20-, 50-, and 100-year return period rainfall scenarios. The results show that node overflow, water depth, and inundation area increase proportionately with the growing return periods. Water depths are mostly predicted to be shallow and surface flows generally occur in the urban road network due to its low-lying nature. The simulation result of the coupled model proves to be reliable and suggests that urban surface water flooding could be accurately simulated by using this methodology. Adaptation measures (upgrading of the urban drainage system) can then be targeted at specific locations with significant overflow and flooding.
\end{abstract}

Jie Yin

jyin@geo.ecnu.edu.cn

1 Key Laboratory of Geographic Information Science (Ministry of Education), East China Normal University, Shanghai 200241, China

2 School of Geographic Sciences, East China Normal University, Shanghai 200241, China

3 Institute of Eco-Chongming, East China Normal University, Shanghai 200241, China

4 Department of Geography, Loughborough University, Loughborough LE11 3TU, UK
Keywords ECNU Flood-Urban model ·

Shanghai - Storm water management model (SWMM) . Urban pluvial flooding

\section{Introduction}

Urban pluvial flooding is attracting growing public concern and research focus worldwide. In the context of global environmental change, the urban hydrological environment has evolved under the combined effect of natural and anthropogenic factors (Du et al. 2012; Yin et al. 2016a; Gu et al. 2019). There is a growing consensus that climate change will result in more extreme precipitation events (IPCC 2012, 2013; Zhang, Gu et al. 2018). Moreover, rapid urban expansion significantly increases impervious surface areas, causing sharp increases in urban discharge and runoff (Du et al. 2012; Zhang, Villarini et al. 2018). In addition, the existing drainage network systems in most cities are outdated and rapid urbanization has significantly outpaced the construction of urban infrastructure, thus making cities more vulnerable to pluvial flooding. These combined factors result in an increase in the frequency and severity of urban pluvial flooding.

As a critical infrastructure component in urban environments, the storm sewer system is responsible for draining excess surface runoff in cities. According to the Code for the Design of Outdoor Wastewater Engineering (GB 50014-2006), ${ }^{1}$ the capacity of urban drainage systems in China is generally designed to cope only with 1- to 3 -year return period rainfall, which is significantly lower

\footnotetext{
${ }^{1}$ Code for the Design of Outdoor Wastewater Engineering (GB 50014-2006): http://www.mohurd.gov.cn/wjfb/201607/t20160712_ 228080.html.
} 
than the design standards (5- to 10-year) of urban drainage systems in countries such as the United States, the United Kingdom, and Japan. Given insufficient drainage capacity, torrential rains can overwhelm the storm sewer system, leading to extensive surface water flooding throughout cities, particularly in developing countries. In recent years, the "ocean views in the city" have become a new landscape in more than half of China's cities in the flood season (Xia et al. 2017). In September 2013, for example, an extreme rainfall event occurred in Shanghai, with precipitation of $124 \mathrm{~mm} / \mathrm{h}$ in the Pudong New Area, resulting in flood inundation of more than 80 roads with water depths of $200-500 \mathrm{~mm}$ and associated widespread disruption of urban traffic. In order to protect against the increasingly severe storms and urban floods, the concept and framework of the "sponge city" have been proposed, based on the ecological drainage and pipe network drainage system. The Chinese government is also actively promoting the pilot construction of sponge cities (Wang et al. 2018).

The simulation of urban surface water flooding is more complex than that of traditional hydrologic modeling in river basins, and it is necessary to comprehensively consider the hydrodynamic processes in urban areas, both at the surface and underground. Since the 1960s, the development of urban pluvial flood modeling has gone through several stages, including the development of hydrological methods, 1D hydrodynamic methods, 1D/2D coupled hydrodynamic methods, and, more recently, Geographic Information System (GIS)-based simplified hydrodynamic methods. Traditional urban stormwater models-such as the storm water management model (SWMM), the storage treatment overflow runoff model (STORM), and the Wallingford models-generally simulate the urban rainfall-runoff process using hydrological methods or 1D hydraulic modeling of urban drainage networks. The main shortcoming of these models is that $2 \mathrm{D}$ surface water flooding cannot be simulated, and thus the location and extent of inundated areas cannot be determined for urban flood management.

During the past decades, the SWMM has been linked with 2D models (first by Hsu et al. 2002), which was unidirectional from sewer to surface. Some commercial software has also coupled 2D hydrodynamic modules and developed a new generation of 1D/2D coupled urban stormwater models such as PC-SWMM (the updated version of the SWMM), InfoWorks (the updated version of Wallingford), Sobek Urban, MIKE-Urban, and TUFLOW. In these new models, the output of the 1D module is used as the input boundary condition of the $2 \mathrm{D}$ module to simulate the overflow process on the surface (Phillips et al. 2005; Bolle et al. 2006; Leandro et al. 2009; Seyoum et al. 2012). However, this type of model usually requires an unstructured mesh to represent the urban topography. The modeling is very complex and most models are not freely available (Yin et al. 2015). In recent years, GIS-based urban flood inundation models have become popular in the academic field and research applications of flood modeling. $\mathrm{Yu}$ and Coulthard (2015) established an urban pluvial flood model (FloodMap-HydroInundation2D), which uses a high-resolution digital elevation model (DEM) for the 2D numerical modeling of urban rainfall-runoffprocesses, but the model uses a generalized scheme for the urban drainage capacity and does not consider the hydrodynamic processes of the storm sewer system. In order to overcome the shortcomings of the above-mentioned two types of models, some researchers have combined the open-access 1D urban stormwater model with the GIS-based 2D flood model to simulate the flood inundation processes. For example, the SWMM was linked bi-directionally with P-DWAVE, a 2D overland flow model (Leandro et al. 2014; Leandro and Martins 2016). Wu et al. (2017) combined the SWMM and LISFLOOD-FP models to simulate future urban pluvial flooding in the city of Dongguan, Guangdong Province, but such case studies and the associated technical methods are still very limited.

In this study, we coupled the underground 1D stormwater model (SWMM) with a newly developed 2D urban flood inundation model (ECNU-Flood Urban) to conduct a scenario analysis of stormwater flooding in downtown Shanghai under different precipitation return periods. We compared the simulation results with the modeling outputs of FloodMap-HydroInundation2D, which is well established and has a similar 2D model structure but with a different treatment of urban drainage, to determine the feasibility and robustness of the 1D/2D coupled model. The proposed method extends the existing methods and provides a numerical simulation of urban storm flooding. The results may serve as a technical reference for Chinese cities in terms of flood control, disaster risk reduction, and sponge city construction and have important scientific and practical significance. An up-to-date framework of surface flood modeling for cities is established. This provides a strong scientific basis for urban flood risk management for various stakeholders and the construction of sponge cities in an uncertain future.

Section 2 introduces the geography of the study area. Section 3 provides the materials and methods, including the available data and the description of coupled modeling. Section 4 presents the results and discussion, and Sect. 5 summarizes the key conclusions. 

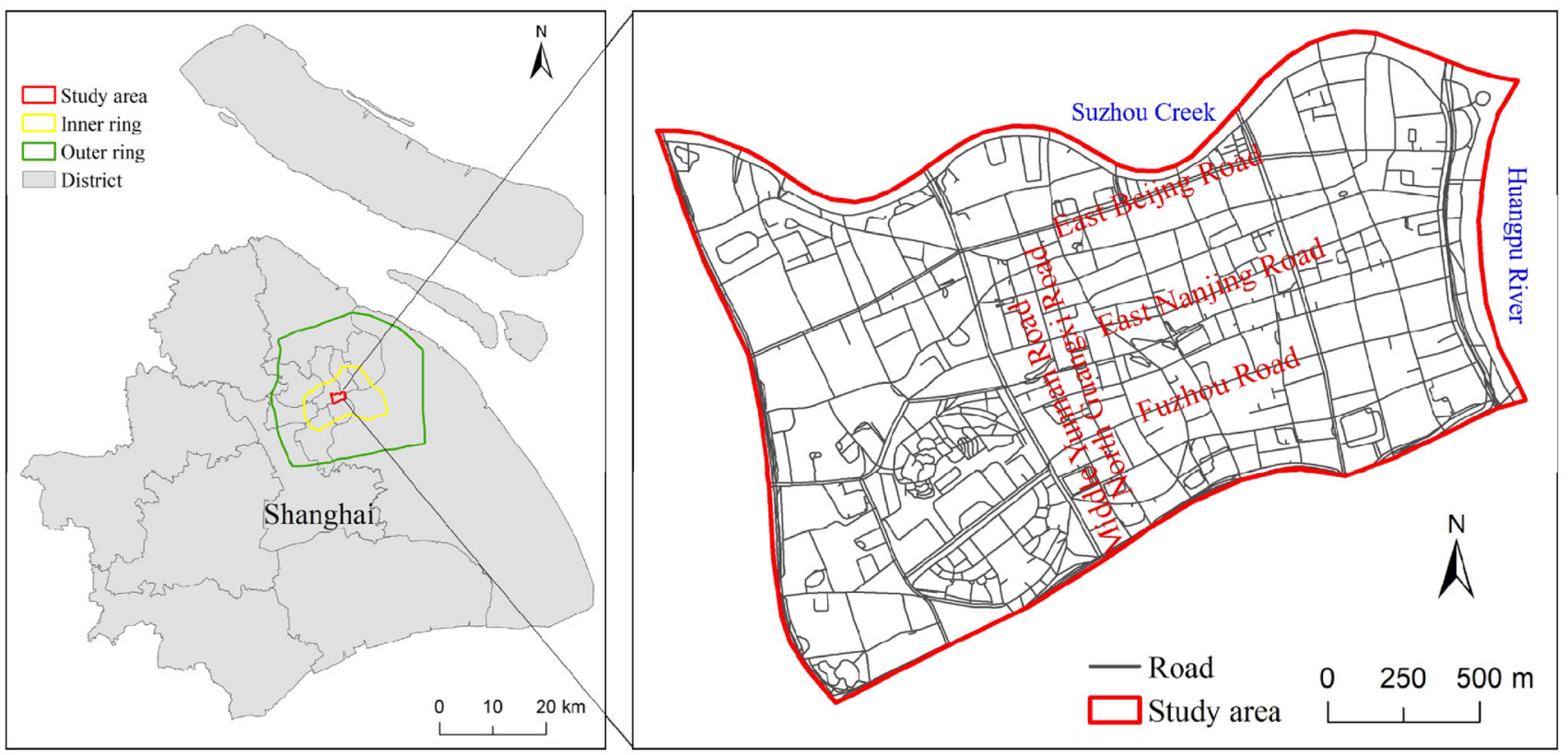

Fig. 1 Location of the study area in Shanghai

\section{Study Area}

The central business district (CBD) of East Nanjing Road, which is the downtown area of Shanghai, was chosen as the study site because it has a high risk of urban pluvial flooding. The study area is located in the North Huangpu District and borders the Huangpu River to the east and Suzhou Creek to the north (Fig. 1). It covers approximately $3.2 \mathrm{~km}^{2}$ and has low elevation (on average about $3 \mathrm{~m}$ above the Wusong Datum ${ }^{2}$ ). The region is located in a northern subtropical monsoon climate zone characterized by cyclonic storms and intense precipitation that frequently occur in the flood season from July to September. According to the historical records, severe pluvial flooding events have occurred in Shanghai 272 times from AD 251 to 2000 , accounting for over half of the total flood disasters (Quan 2014).

In order to cope with the adverse impacts of surface water flooding in the downtown area of Shanghai, an urban drainage system was established and has been continuously expanded and upgraded since 1990s. However, problems such as lagging construction of the drainage pipe network system, small diameter of some pipelines, and low drainage capacity result in an inability of the storm sewer system in the central urban area to meet the increasing drainage demand; these are the major reasons for urban rainstorm waterlogging. The influence of human activities on the structure of the urban river network, such as garbage

\footnotetext{
${ }^{2}$ Wusong Datum is the average lowest sea levels measured during 1871-1900 at the Wusong gauge station.
}

dumping and land reclamation, also greatly reduce the retention, storage, and drainage capacity of stormwater in the urban area when waterlogging occurs. In addition, rapid urban expansion significantly increases the impervious surface area, which sharply reduces the infiltration capacity of the rainstorm runoff and makes it difficult to discharge the water naturally.

\section{Materials and Methods}

Urban pluvial flooding processes can be categorized as surface and underground flooding. When extreme precipitation events occur and urban surface runoff exceeds the drainage capacity, the stormwater flow spills out of the ground from the underground pipe network through manholes or pump stations, resulting in urban surface water flooding. In this study, the SWMM was used to simulate the $1 \mathrm{D}$ water flow movement in the drainage pipelines and the process of water overflow on the ground was simulated using the ECNU-Flood Urban model. The output of the 1D hydrodynamic model was used as the input to drive the $2 \mathrm{D}$ surface flood modeling.

\subsection{Rainfall Scenarios}

Rainfall is the most important input variable of urban pluvial flooding and the parameters of rainfall intensity and rainfall duration were considered. The Shanghai Municipal Engineering Design Institute (2003) developed the following rainstorm intensity equation that is based on the 
precipitation of a specified return period $(5,10,20,50$, 100 years):

$q=1995.84\left(p^{0.30}-0.42\right) /(t+10+7 \lg P)^{0.82+7 \lg P}$

where $q$ is the rainfall intensity; $P$ is the return period of rainfall; and $t$ is the duration of rainfall.

The Chicago design storm method, developed for a study of stormwater flooding in Chicago by Keifer and Chu (1957), describes the temporal variations of rainfall based on the rainfall intensity before and after the peak. The Chicago design storm data represent a time series of the storm intensity and the rain peak coefficient $r(0<r<1)$ and are used to describe when the rainfall peak occurs. The rainfall duration is divided into the pre-peak time $t_{x}$ and the post-peak time $t_{y}$. Considering the local conditions in Shanghai, the rain peak coefficient is empirically set at 0.4 (Yin et al. 2016b). Combined with the Shanghai rainstorm intensity equation, the design storm with 2 -h duration is generated for specified return periods. The Chicago design storm is defined as follows:

$i_{\mathrm{a}}=\frac{a \times\left[\frac{(1-c) \times t_{y}}{1-r}+b\right]}{\left(\frac{t_{y}}{1-r}+b\right)^{c+1}}$

$i_{\mathrm{b}}=\frac{a \times\left[\frac{(1-c) \times t_{x}}{r}+b\right]}{\left(\frac{t_{x}}{r}+b\right)^{c+1}}$

where $i_{\mathrm{a}}, i_{\mathrm{b}}$ are the rainfall intensity before and after the rain peak $(\mathrm{mm} / \mathrm{min}) ; t_{x}, t_{y}$ are the time intervals before and after the rain peak (min); $r$ is the rain peak coefficient $(0<r<1)$; and $a, b$, and $c$ are the local parameters in the storm intensity formula.

\subsection{Storm Water Management Model (SWMM) Modeling}

In this study, the SWMM developed by the U.S. Environmental Protection Agency (EPA) was used to simulate the flow in the underground drainage system. The storm water management model is a 1D dynamic rainfallrunoffmodel that can simulate runoff quantity and quality from primarily urban areas. Since its development, the SWMM has been used in thousands of storm sewer and stormwater studies throughout the world, including the evaluation of the impact of inflow and infiltration on storm sewer overflows. The flow calculation in the drainage system usually describes the flow movement in the pipeline in a 1D form, allowing the water flows from one node to the next through the pipe.

In general, channel and pipe flow routings are governed by the Saint-Venant equations. In the transport component, the SWMM solves the Saint-Venant equation using the implicit finite difference method and successive approximation. The flow equation is defined as follows:

$\frac{\partial A}{\partial t}+\frac{\partial Q}{\partial x}=0$

$\frac{Q}{g A} \cdot \frac{\partial}{\partial x}\left(\frac{Q}{A}\right)+\frac{1}{g A} \cdot \frac{\partial Q}{\partial t}+\frac{\partial h}{\partial x}+S_{f}-S_{0}=0$

where $Q$ is the outflow $\left(\mathrm{m}^{3} / \mathrm{s}\right) ; A$ is the cross-sectional area of the water $\left(\mathrm{m}^{2}\right) ; h$ is the water depth $(\mathrm{m})$ in the pipeline; $t$ is time (s); $x$ is the length of the pipe along the water flow direction (m); $S_{f}$ is the resistance slope; and $S_{0}$ is the bottom slope of the pipeline.

The drainage network data used in this study were obtained from the Shanghai Municipal Sewerage Company, including the geographic and geometric information of pipes, nodes, and manholes; the attributes include the network length, pipe diameter (or length and width), elevation at the beginning of the pipeline, depth of the manholes, and ground elevation. The diameters of the pipes ranged from 300 to $400 \mathrm{~mm}$, and the depths of the manholes ranged from 1.2 to $1.4 \mathrm{~m}$. There were 620 drainage pipe sections in the modeling area and 500 inspection well nodes (including 5 pump stations), with a total length of about $45 \mathrm{~km}$. To reduce the modeling complexity and computational cost, the urban drainage system was simplified in the SWMM. Using the Thiessen polygon method in ArcGIS, the study area was automatically divided into 495 subcatchments corresponding to the inspection well nodes. The subcatchments were further modified according to the distribution of the roads and pipe networks in the study area (Fig. 2).

\subsection{Model Coupling}

The SWMM model was used to calculate the hydrodynamics in the pipe network, and the time series (for example, 1, 5, or 15 min intervals) of the surcharges of the storm sewer system (manholes) was then used as the flow boundary condition of the 2D surface water flooding model to achieve the coupling of the 1D and 2D models (Fig. 3). We developed a SWMM link to define the location of manhole inflow in the ECNU Flood-Urban model. It should be noted that this is only a loosely coupled scheme of urban pluvial flood modeling. The SWMM and ECNU FloodUrban models were run, respectively, and thus the dynamic flow exchanges between the 1D and 2D models were ignored.

\subsection{Surface Flood Inundation Modeling}

To determine the surface flood inundation in the urban area, we developed a new raster-based 2D hydrodynamic 


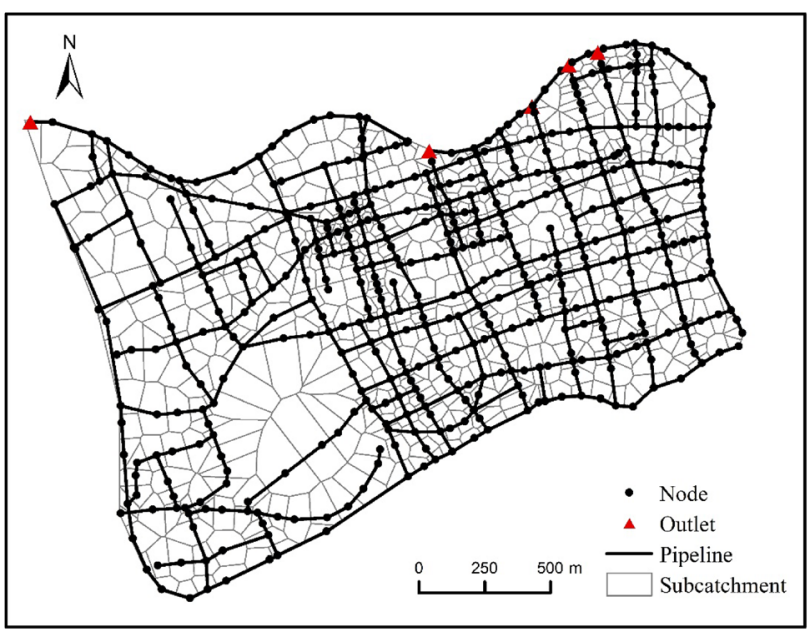

Fig. 2 Simplification of the urban drainage network in the Shanghai study area

model (ECNU-Flood Urban). The urban inundation model has the same structure as the diffusion-wave treatment of Bradbrook et al. (2004) and $\mathrm{Yu}$ and Lane (2006a, 2006b, 2011). The ECNU-Flood Urban model is coded in JAVA and is based on the discretization of the Manning equation; it ignores the inertial and advection forces of water flow. The general form of the Manning equation is as follows:

$Q=\frac{A R^{2 / 3} S^{0.5}}{n}$

where $Q$ is the flow; $A$ is the cross-sectional area; $R$ is the hydraulic radius; $n$ is Manning's roughness coefficient; and $S$ is the energy slope. In a regular grid, the flow area is calculated as follows:

$A=w \times d$

where $w$ is the width of the grid; and $d$ is the flow depth. The hydraulic radius $R$ is equal to the depth of the grid $(d)$, and thus the Manning equation can be expressed as follows:
$Q=\frac{w d^{5 / 3} S^{0.5}}{n}$

Considering a regular grid and the adjacent four cells, the orthogonal directions of the grids are defined as $i$ and $j$. The energy slope $S$ in each orthogonal direction is represented by the difference in water levels between the grid centers. If the slope of the source grid toward the other adjacent grids is positive, water is allowed to flow out of the grid.

$S_{i}=\frac{h_{i, j}-h_{i \pm 1, j}}{w}$

$S_{j}=\frac{h_{i, j}-h_{i, j \pm 1}}{w}$

The flow direction is determined by the vector sum of the energy slope $S_{i}$ and $S_{j}$. Therefore, the energy slope $S$ can be calculated as:

$S=\sqrt{S_{i}^{2}+S_{j}^{2}}$

In each of the four directions, the effective depth is represented by the water surface elevation in the source grid that is higher than the two ground elevations in the $i$ or $j$ direction:

$d_{i}=h_{i, j}-\max \left|g_{i, j}, g_{i \pm 1, j}\right|$

$d_{j}=h_{i, j}-\max \left|g_{i, j}, g_{i, j \pm 1}\right|$

where $d$ is the effective depth; $h$ is the water surface level; and $g$ is the ground level. The effective depth in the outflow direction is expressed as the arithmetic mean of the effective depths of both flows in the direction of the steepest slope:

$d=\frac{d_{i} S_{i}^{2}+d_{j} S_{j}^{2}}{S^{2}}$

Manning's equation is then solved in the $i$ and $j$ directions of the grids, and the flows into and out of each grid at each time step are calculated as follows:
Fig. 3 Coupled modeling of urban pluvial flooding in the Shanghai study area. DSM: digital surface model

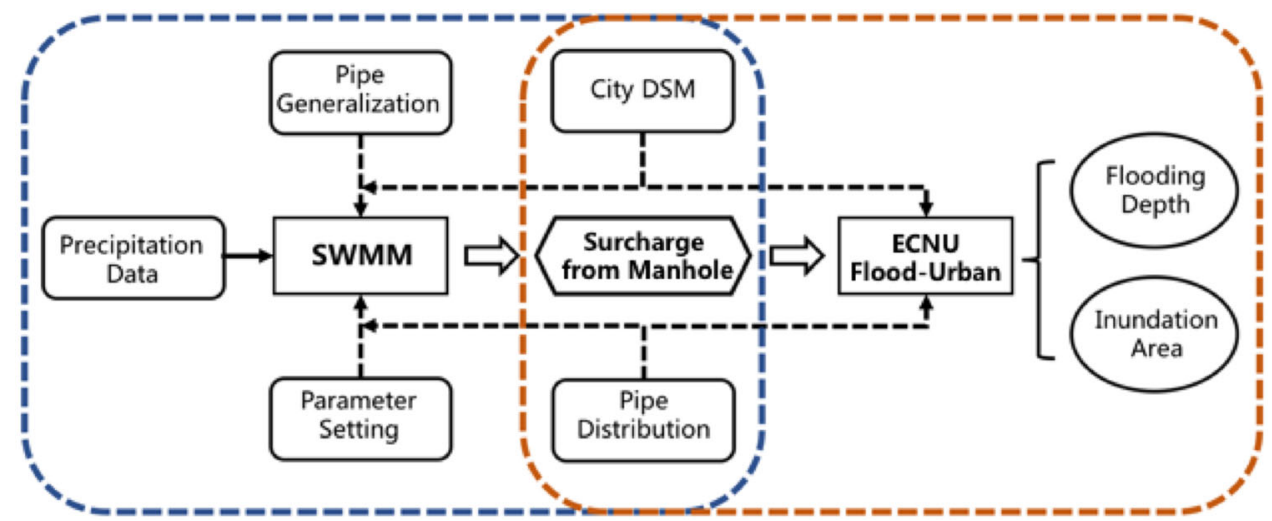




$$
\begin{gathered}
Q_{i}=Q \frac{S_{i}}{S}=\frac{w d^{5 / 3} S_{i}}{n S^{0.5}}=\frac{w d^{5 / 3}\left(\frac{h_{i, j}-h_{i \pm 1, j}}{w}\right)}{n\left[\left(\frac{h_{i, j}-h_{i \pm 1, j}}{w}\right)^{2}+\left(\frac{h_{i, j}-h_{i, j \pm 1}}{w}\right)^{2}\right]^{1 / 4}} \\
Q_{j}=Q \frac{S_{j}}{S}=\frac{w d^{5 / 3} S_{j}}{n S^{0.5}}=\frac{w d^{5 / 3}\left(\frac{h_{i, j}-h_{i, j \pm 1}}{w}\right)}{n\left[\left(\frac{h_{i, j}-h_{i \pm 1, j}}{w}\right)^{2}+\left(\frac{h_{i, j}-h_{i, j \pm 1}}{w}\right)^{2}\right]^{1 / 4}}
\end{gathered}
$$

The flow depth change in each of the grids is determined at the start of each time step:

$\Delta d=\frac{\left(\sum_{d=1}^{4} Q_{\mathrm{in} i, j}^{d}-\sum_{d=1}^{4} Q_{\text {out } i, j}^{d}+Q_{\text {inflow }}\right) \Delta t}{w}$

where $\Delta t$ is the time step.

The input into the ECNU-Flood Urban model includes model parameters, topographic data, and the boundary condition. The main model parameter used in this study is Manning's roughness coefficient $n$. An empirical Manning's $n$ value of 0.04 , which has provided good predictions in previous studies, was used in the simulation of the design flood scenarios; the value reflects the effect of urban features on flood routing (Yin et al. 2016b). A high-resolution airborne LiDAR digital surface model (DSM) provided by the Shanghai Survey Bureau was used for the topographic data of the study site. The original LiDAR point cloud data had a horizontal resolution of about $0.6 \mathrm{~m}$ and a vertical resolution of $0.1-0.2 \mathrm{~m}$. The TerraSolid software was used for quality control and hierarchical processing to remove specific urban surface features such as trees. Finally, the remaining data in the point cloud were converted into a standard grid resolution of $2 \mathrm{~m}$. The drivers of the coupled model are the rainfall scenarios, but the infiltration/evapotranspiration in urbanized areas can be neglected during short-term heavy rainfall. The model was set up to run four hours until a steady state of urban flooding was reached by the end of the simulation.

\section{Results and Discussion}

The hydrodynamic characteristics of rainfall-runoffprocesses in urban environments are investigated successively in the sewer system (Sect. 4.1) and on the ground surface (Sect. 4.2). The coupled modeling outputs of urban pluvial flooding are further compared with crowd-sourced data and the simulated results derived from FloodMap-HydroInundation2D (Sect. 4.3), and the key findings are discussed.

\subsection{Storm Water Management Model (SWMM) Modeling}

The rainfalls of different return periods are input into the SWMM model as the driving condition to simulate the water flows in the storm sewer system of the study area. The overflow nodes and overloaded pipelines were determined to evaluate the drainage capacity of the pipe network. The simulation results are shown in Table 1 .

The surface runoff, as expected, increases as the rainfall increases. This is largely due to the significant impervious surface areas and the insufficient drainage capacity in the study area. Specifically, there are 253, 276, 282, 301, and 313 overflow nodes under the rainfall events with return periods of $5,10,20,50$, and 100 years. The total overflow of the sewer system is predicted to increase from $94,928 \mathrm{~m}^{3}$ at the 5 -year return period to $222,764 \mathrm{~m}^{3}$ at the 100 -year return period. These results indicate that there is a proportionate and linear relationship between the rainfall magnitudes and the total overflow and surface runoff of the pipe network in the study area. More than $30 \%$ of the pipeline network is overloaded when the rainstorm return period is five years or longer, because the rainfall intensity exceeds the designed drainage capacity of the pipes. However, an important finding is that the differences of overloaded pipelines among various return period events are small. This suggests that overflow mainly occurs through a limited number of terminal nodes for each simulation, albeit with a different rainfall magnitude corresponding to a different return period.

The spatial distribution of the surcharges of the drainage pipe network at the first hour of simulations under different rainfall return periods is shown in Fig. 4. The varying degrees of node overflow in the drainage network are highly correlated to the intensity of the rainfall. For a 5-year return period, there is a large number of overflow nodes, mainly along the East Beijing Road, West Nanjing Road, and Fuzhou Road. As the return period increases, overflow nodes gradually spread across the study area, with a significant rise in the amount of surcharges. Under a 100-year return period event, over 50 nodes, accounting for $16 \%$ of the total, are predicted to overflow more than $0.8 \mathrm{~m}^{3} / \mathrm{s}$. However, similar patterns of the overflow nodes of the sewer system can be observed among the five scenarios, further confirming the simulation results of drainage capacity in Table 1 . The predicted surcharges of the drainage network are relatively small in the southwest part (that is, the People's Park) of the region under all rainfall return periods, as the overflow peaks in the large open green spaces occur at around $\sim 45 \mathrm{~min}$ of simulations and then rapidly decrease. 
Table 1 Storm water management model (SWMM) simulation results in different rainstorm return periods for the Shanghai study area

\begin{tabular}{llllcl}
\hline $\begin{array}{l}\text { Return period } \\
\text { (years })\end{array}$ & $\begin{array}{l}\text { Total rainfall } \\
(\mathrm{mm})\end{array}$ & $\begin{array}{l}\text { Total runoff } \\
(\mathrm{mm})\end{array}$ & $\begin{array}{l}\text { Number of overflow } \\
\text { nodes }\end{array}$ & $\begin{array}{l}\text { Total overflow } \\
\left(\mathrm{m}^{3}\right)\end{array}$ & $\begin{array}{l}\text { Proportion of overloaded pipelines } \\
(\%)\end{array}$ \\
\hline 5 & 67.7 & 49.72 & 253 & 94,928 & 32.65 \\
10 & 79 & 58.53 & 276 & 121,834 & 33.22 \\
20 & 90.8 & 67.78 & 282 & 150,294 & 35.37 \\
50 & 107.3 & 80.66 & 301 & 190,241 & 36.57 \\
100 & 120.6 & 91.1 & 313 & 222,764 & 38.09 \\
\hline
\end{tabular}

\subsection{Surface Water Flood Modeling}

The 1D and 2D models are coupled and the surface water flooding under different rainfall scenarios is simulated. The result of maximum inundation (extent and depth) for each simulation is shown in Fig. 5. The general pattern of surface water flooding is characterized by a high degree of consistency among the five scenarios. In each simulation, the inundation with shallow water depth (generally less than $0.3 \mathrm{~m}$ ) can be observed mostly in the low-lying road network of the study area. The maximum inundation area is expected to slightly increase from $60,500 \mathrm{~m}^{2}$ for a 5 -year rainfall event to $106,536 \mathrm{~m}^{2}$ for a 100 -year rainfall event, because of the minor differences among the predicted surcharges of the sewer system under each rainfall scenario. Although the surface water flooding is associated with significant overflow from the drainage network, roads around the People's Park are found to be subject to obvious flood inundation. This can be explained by the mild relief, flat topography, and the relatively high drainage capacity $(36-49.6 \mathrm{~mm} / \mathrm{h})$, suggesting that pluvial flood inundation is greatly dependent on the interplay among rainfall intensity, topographic features, and drainage capacity.

Figure 6 shows the time series of the predicted wet area for all flood scenarios. The time-area curves are in line with each other, suggesting similar inundation dynamics throughout the simulations. Furthermore, node overflow leads to a proportionate and linear effect on the time evolution of the flood inundation. Generally, surface water flooding occurs at the first hour of simulations, and then rapidly extends along the road network at the second hour when a large amount of water overwhelms the drainage network. A steady state is reached afterwards, but the flood extent continues to slightly increase till the end of each simulation, even without any surcharges from the sewer system.

\subsection{Model Validation and Comparison}

A complete picture of observed flood extent and height (for example, remote sensing images, reliable field surveys, and high-water marks) is not available for the study area. Instead, the SWMM-ECNU Flood-Urban coupled modeling scheme is validated by comparing the model prediction of a severe pluvial flood event that occurred in August 2011 with flood incidents reported by the public. Distributed precipitation data are used as input to drive the 1D/ 2D coupled modeling. Predicted maximum inundation and the crowd-sourced flood points are presented in Fig. 7. The result shows that all of the 17 reported flood locations fall within the simulated inundation areas with a water depth higher than $40 \mathrm{~cm}$. In addition, social media also reported that some main roads such as East Nanjing Road were heavily inundated during the event. These findings suggest a good match between the model estimates and observed flood records.

The coupled modeling of the SWMM and ECNU FloodUrban models is comparable to the 2D hydrodynamic modeling such as the FloodMap-HydroInundation2D simulation (Fig. 5 in Yin et al. 2016a). The major difference between these two methods is the drainage setting. The SWMM model in the coupled modeling is used to simulate the dynamic process of the water flowing in the urban storm sewer system, while the amount of runoff loss is simply calculated in the FloodMap-HydroInundation2D model by scaling the drainage capacity for each time step with an assumption that the sewer system drains water away at the maximum design capacity. In practice, urban sewer system is always difficult to achieve the maximum design drainage capacity. Therefore, the maximum inundation areas during the August 2011 pluvial flood event obtained from the 1D/2D coupled modeling are larger than those directly predicted by the FloodMapHydroInundation2D.

\section{Conclusion}

In this study, a new methodology for urban pluvial flood modeling was developed by loosely coupling the 1D SWMM model and the 2D surface water flood model (ECNU Flood-Urban). Using a recent pluvial flood event 


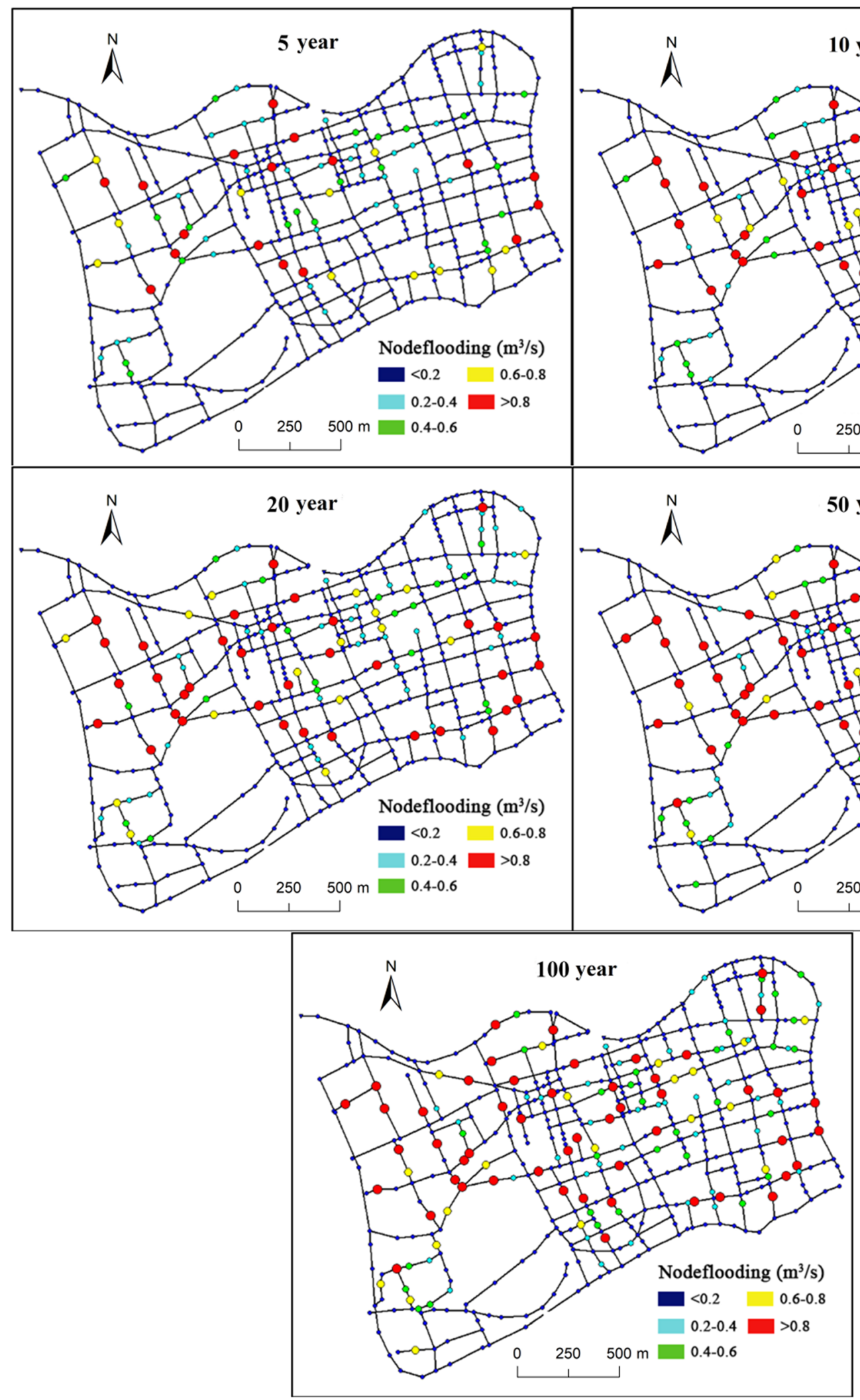

Fig. 4 Node overflows of the drainage network at different rainstorm return periods in the Shanghai study area 


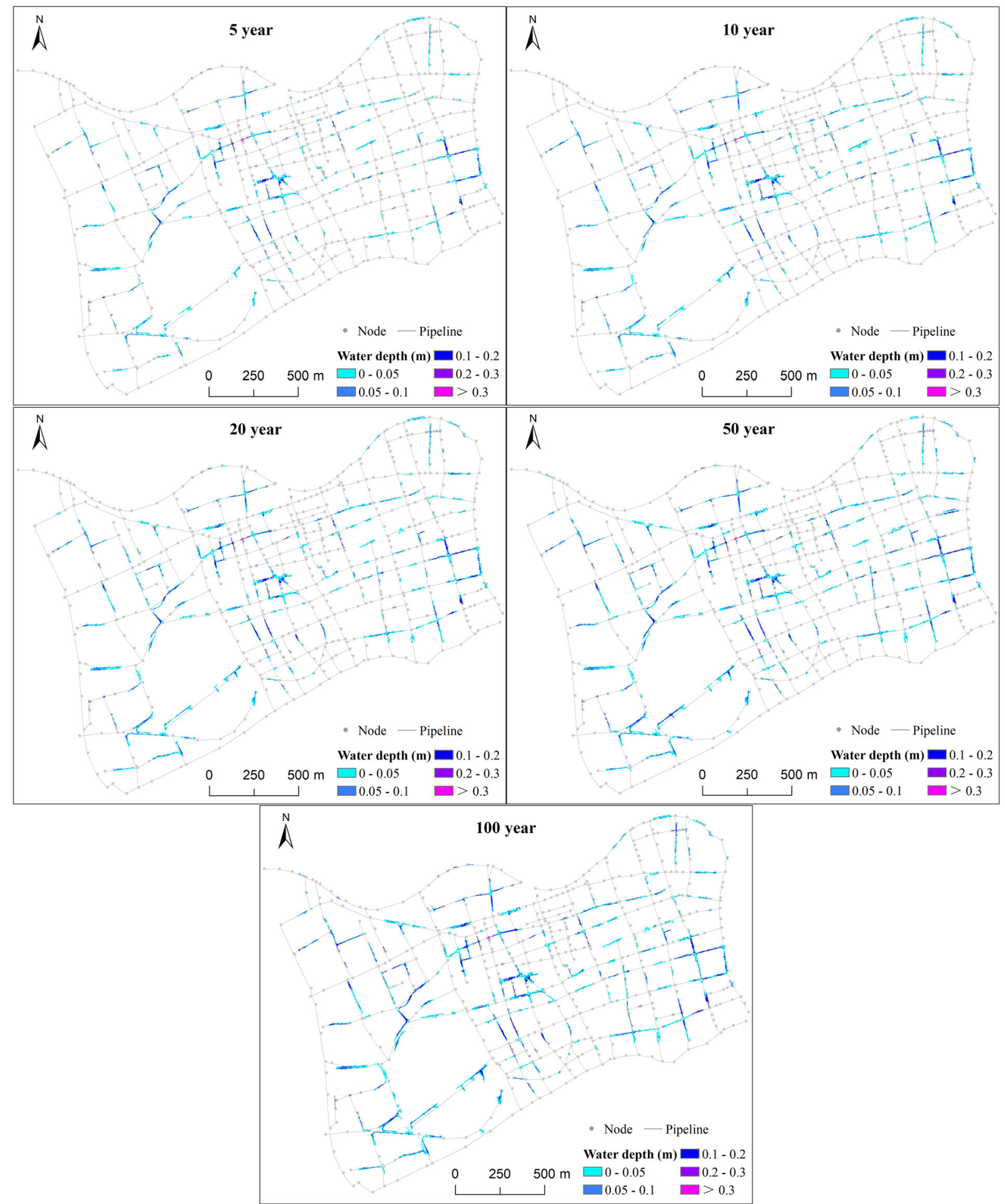

Fig. 5 Maximum water depth and inundation area at different rainfall return periods in the Shanghai study area

that occurred in the city center of Shanghai, we validated the coupled modeling through the comparison between model prediction and crowd-sourced data. The approach was further used to simulate urban pluvial flooding for the study area under rainfall scenarios with different return periods. A number of conclusions can be drawn. First, the inundation predicted by the coupled modeling of the SWMM and ECNU Flood-Urban models agrees well with 


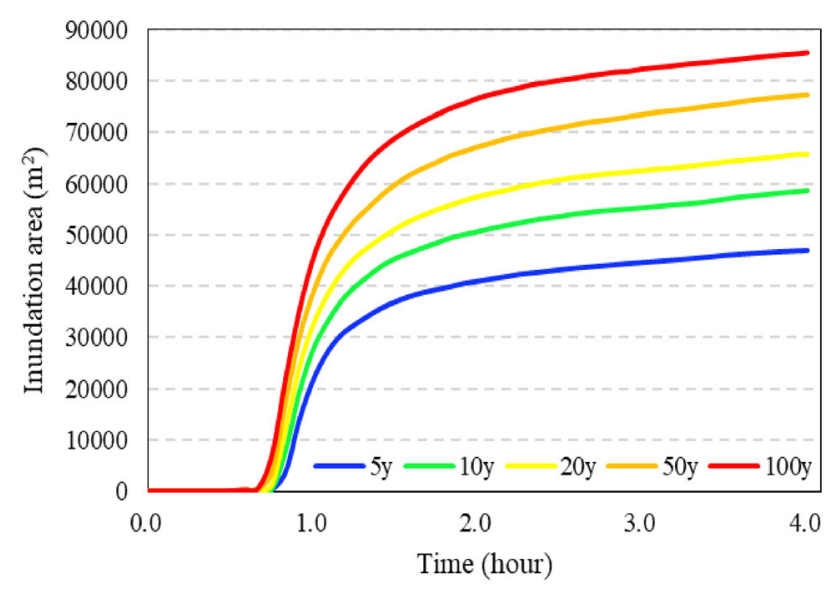

Fig. 6 Time series of inundation area throughout the simulation for each scenario in the Shanghai study area

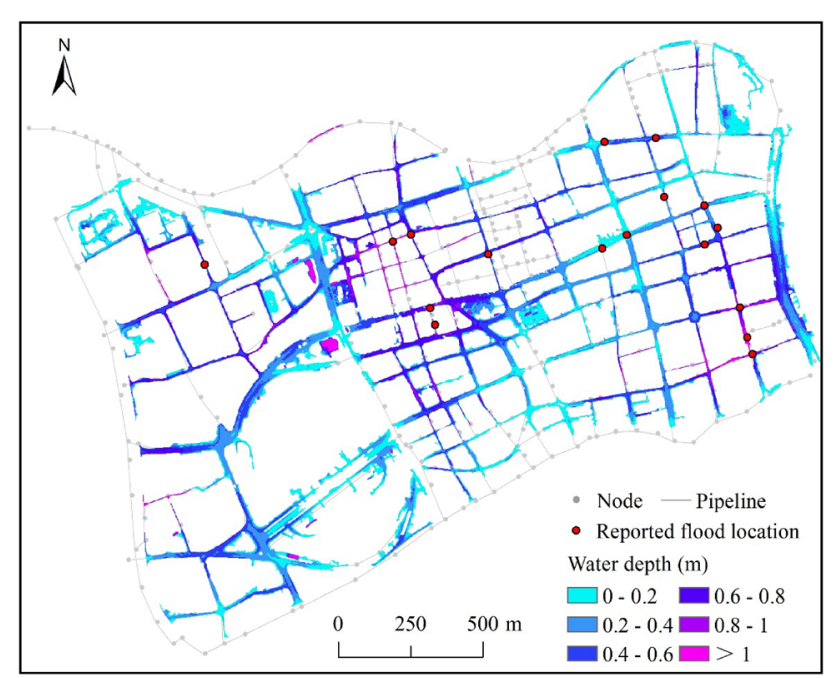

Fig. 7 Predicted maximum inundation overlain with reported flood locations during the August 2011 pluvial flood event in the Shanghai study area

the observed flood locations, and is larger than those directly simulated by the 2D hydrodynamic modeling (FloodMap-HydroInundation2D). Second, the risk of overloading the sewer system and associated surface water flooding is determined by the interaction among rainfall intensity, topographic features, and drainage capacity. Third, surface water flooding occurs extensively in the lowlying road network with relatively shallow water depth.

The simplified modeling method presented here could be easily applied in other flood-prone cities, compared to other 1D/2D coupled modeling schemes. It may contribute to better understanding of insufficient drainage capacity of urban sewer systems, and thus help to inform adaptation measures for sustainable flood risk management. However, to arrive at more reliable results, future studies could be conducted in the following aspects: (1) tightly $1 \mathrm{D} / 2 \mathrm{D}$ coupled modeling should be developed to explore the dynamic flow exchanges between the 1D and 2D models; (2) full 2D solutions for the treatment of flood routing would be a significant advance, particularly for including the inertial effect of water flow; and (3) the use of massive online social networks on platforms like Weibo and WeChat would enable big data collection for model validation.

Acknowledgements This study was supported by the National Key Research and Development Program of China (Grant Nos.: 2018YFC1508803, 2017YFE0107400, 2017YFE0100700), the National Natural Science Foundation of China (Grant Nos.: $41871164,51761135024)$, the National Social Science Fund of China (Grant No.: 18ZDA105), the Humanities and Social Sciences Project of the Ministry of Education of China (Grant No.: 17YJAZH111), the Key Project of Soft Science Research of Shanghai (Grant No.: 19692108100), and the Fundamental Research Funds for the Central Universities (Grant Nos.: 2018ECNU-QKT001, 2017ECNUKXK013).

Open Access This article is licensed under a Creative Commons Attribution 4.0 International License, which permits use, sharing, adaptation, distribution and reproduction in any medium or format, as long as you give appropriate credit to the original author(s) and the source, provide a link to the Creative Commons licence, and indicate if changes were made. The images or other third party material in this article are included in the article's Creative Commons licence, unless indicated otherwise in a credit line to the material. If material is not included in the article's Creative Commons licence and your intended use is not permitted by statutory regulation or exceeds the permitted use, you will need to obtain permission directly from the copyright holder. To view a copy of this licence, visit http://creativecommons. org/licenses/by/4.0/.

\section{References}

Bolle, A., A. Demuynck, R. Bouteligier, S. Bosch, A. Verwey, and J. Berlamont. 2006. Hydraulic modelling of the two-directional interaction between sewer and river systems. In Proceedings of the international conference on urban drainage modelling \& the international conference on water sensitive urban design, ed. A. Delectic, and T. Fletcher, 896-903. Victoria, Australia: Monash University Publishing.

Bradbrook, K.F., S.N. Lane, S.G. Waller, P.D. Bates. 2004. Two dimensional diffusion wave modelling of flood inundation using a simplified channel representation. International Journal of River Basin Management 2(3): 211-223.

Du, J., L. Qian, H. Rui, T. Zuo, D. Zheng, Y. Xu, C.Y. Xu. 2012. Assessing the effects of urbanization on annual runoff and flood events using an integrated hydrological modeling system for Qinhuai River basin, China. Journal of Hydrology 464-465: 127-139.

Gu, X., Q. Zhang, J. Li, V.P. Singh, J. Liu, P. Sun, and C. Cheng. 2019. Attribution of global soil moisture drying to human activities: A quantitative viewpoint. Geophysical Research Letters 46(5): 2573-2582.

Hsu, M.-H., S.H. Chen, and T.-J. Chang. 2002. Dynamic inundation simulation of storm water interaction between sewer system and overland flows. Journal of the Chinese Institute of Engineers 25(2): 171-177. 
IPCC (Intergovernmental Panel on Climate Change). 2012. Climate change 2012, the physical science basis. Cambridge: Cambridge University Press.

IPCC (Intergovernmental Panel on Climate Change). 2013. Climate change 2013, the physical science basis. Cambridge: Cambridge University Press.

Keifer, C.J., and H.H. Chu. 1957. Synthetic storm pattern for drainage design. Journal of the Hydraulics Division 83(4): 1-25.

Leandro, J., and R. Martins. 2016. A methodology for linking 2D overland flow models with the sewer network model SWMM 5.1 based on dynamic link libraries. Water Science and Technology 73(12): 3017-3026.

Leandro, J., A.S. Chen, S. Djordjevic, and D.A. Savic. 2009. Comparison of $1 \mathrm{D} / 1 \mathrm{D}$ and $1 \mathrm{D} / 2 \mathrm{D}$ coupled (sewer/surface) hydraulic models for urban flood simulation. Journal of Hydraulic Engineering 135(6): 495-504.

Leandro, J., A.S. Chen, and A. Schumanna. 2014. A 2D parallel diffusive wave model for floodplain inundation with variable time step (P-DWave). Journal of Hydrology 517: 250-259.

Phillips, B.C., S. Yu, G.R. Thompson, and N. de Silva. 2005. 1D and 2D modelling of urban drainage systems using XP-SWMM and TUFLOW. In Proceedings of the 10th international conference on urban drainage, 21-26 August 2005, Copenhagen, Denmark.

Quan, R.S. 2014. Risk assessment of flood disaster in Shanghai based on spatial-temporal characteristics analysis from 251 to 2000. Environment Earth Sciences 72: 4627-4638.

Seyoum, S.D., Z. Vojinovic, R.K. Price, and S. Weesakul. 2012. Coupled 1D and noninertia 2D flood inundation model for simulation of urban flooding. Journal of Hydraulic Engineering 138(1): 23-34

Shanghai Municipal Engineering Design Institute. 2003. Water supply \& drainage design handbook: Urban drainage. Beijing: China Architecture \& Building Press (in Chinese).

Wang, H., C. Mei, J.H. Liu, and W.W. Shao. 2018. A new strategy for integrated urban water management in China: Sponge city. Science China Technological Sciences 61(3): 317-329.

Wu, X., Z. Wang, S. Guo, W. Liao, Z. Zeng, and X. Chen. 2017. Scenario-based projections of future urban inundation within a coupled hydrodynamic model framework: A case study in Dongguan City, China. Journal of Hydrology 547: 428-442.

Xia, J., Y.Y. Zhang, L.H. Xiong, S. He, L.F. Wang, and Z.B. Yu. 2017. Opportunities and challenges of the Sponge City construction related to urban water issues in China. Science China Earth Sciences 60(4): 652-658.

Yin, J., M. Ye, Z. Yin, and S. Xu. 2015. A review of advances in urban flood risk analysis over China. Stochastic Environmental Research and Risk Assessment 29(3): 1063-1070.

Yin, J., D. Yu, and R. Wilby. 2016a. Modelling the impact of land subsidence on urban pluvial flooding: A case study of downtown Shanghai, China. Science of the Total Environment 544: 744-753.

Yin, J., D. Yu, Z. Yin, M. Liu, and Q. He. 2016b. Evaluating the impact and risk of pluvial flash flood on intra-urban road network: A case study in the city center of Shanghai, China. Journal of Hydrology 537: 138-145.

$\mathrm{Yu}$, D., and T.J. Coulthard. 2015. Evaluating the importance of catchment hydrological parameters for urban surface water flood modelling using a simple hydro-inundation model. Journal of Hydrology 524: 385-400.

Yu, D., and S.N. Lane. 2006a. Urban fluvial flood modelling using a two-dimensional diffusion-wave treatment, part 2: Development of a sub-grid-scale treatment. Hydrological Processes 20(7): $1567-1583$.

Yu, D., and S.N. Lane. 2006b. Urban fluvial flood modelling using a two-dimensional diffusion-wave treatment, part 1: Mesh resolution effects. Hydrological Processes 20(7): 1541-1565.

$\mathrm{Yu}, \mathrm{D}$., and S.N. Lane. 2011. Interactions between subgrid-scale resolution, feature representation and grid-scale resolution in flood inundation modelling. Hydrological Processes 25(1): $36-53$.

Zhang, Q., X. Gu, J. Li, P. Shi, and V.P. Singh. 2018. The impact of tropical cyclones on extreme precipitation over coastal and inland areas of China and its association to ENSO. Journal of Climate 31: 1865-1880.

Zhang, W., G. Villarini, G.A. Vecchi, and J.A. Smith. 2018. Urbanization exacerbated the rainfall and flooding caused by hurricane Harvey in Houston. Nature 563(7731): 384-388. 